\title{
Development and Validation of HPLC Method for the Quantification of Atorvastatin in Pharmaceutical Dosage Forms and Biological Fluid
}

\author{
SK Manirul Haque* \\ Department of Chemical \& Process Engineering Technology, Jubail Industrial College, Jubail Industrial City-10099, \\ Saudi Arabia
}

\begin{abstract}
A reverse phase HPLC method was developed for the determination of atorvastatin. The mobile phase involved for the separation was phosphate buffer and acetonitrile with a ratio of 10:1. The HPLC column $\mathrm{C}_{18}$ ODS hypersil column $(250 \mathrm{~mm} \times 4.6 \mathrm{~mm}, 5 \mu \mathrm{m})$ was used and detected at $215 \mathrm{~nm}$. The run time of the current method was 5 minutes with excellent specificity; no interferences were observed in the pharmaceutical dosage form. The process was validated according to ICH guidelines. The linearity of the proposed method was within the range of $0.25-3.8 \mu \mathrm{g} / \mathrm{ml}$. The LOD and LOQ values were found to be 0.21 and $0.64 \mu \mathrm{g} / \mathrm{ml}$. The $\%$ recovery and \%RSD were within the range of $98-100 \%$, and $\pm 2 \%$ for accuracy, precision, robustness, ruggedness results. All the values are acceptable as per ICH guidelines. As well, this enhanced technique was applied to calculate the amount of atorvastatin in human urine samples. Therefore, the present method is reliable for quantifying atorvastatin in quality control samples in academic and pharmaceutical industries and can easily be used in research development and hospitals.
\end{abstract}

Keywords: Atorvastatin; HPLC; ICH; Validation; Pharmaceutical formulations; Human urine.

\section{Introduction}

The atorvastatin is chemically known as calcium; (3R, 5R)-7-[2-(4-fluorophenyl)-3-phenyl-4-(phenyl carbamoyl)-5-propan-2-ylpyrrol-1-yl]-3,5-

dihydroxyheptanoate (Figure 1). .

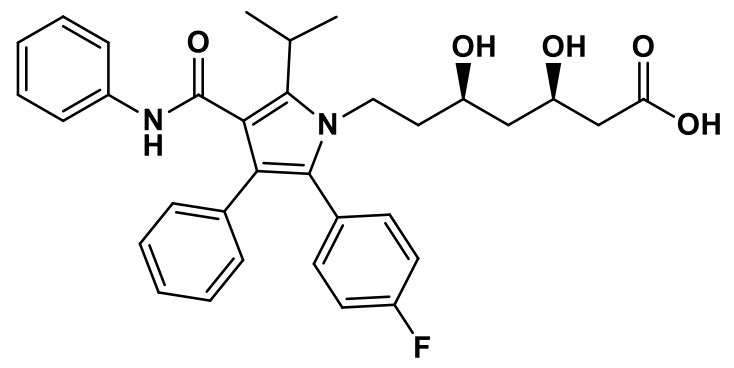

Figure 1. Chemical Structure of Atorvastatin

It is white to off-white powder. It belongs to the medicine group known as statins. It is soluble in methanol, slightly soluble in alcohol, insoluble to very slightly soluble in distilled water, and completely insoluble in water acetonitrile ${ }^{1}$. This reductase inhibitor is familiar as 3-hydroxyl-3-methylglutaryl-coenzyme A (HMG- CoA). Mainly the atorvastatin tablets are used to control weight loss, diet, and stroke. It is also

*Corresponding author: SK Manirul Haque

Email address: Haque_m@jic.edu.sa

DOI: http://dx.doi.org/10.13171/mjc02106301581haque helpful for lowering the chance of a heart attack during the surgery. The statins decrease blood lipid, which includes triglycerides bad cholesterol ${ }^{2-8}$. Primary hypercholesterolemia is indicated in patients who have not responded adequately to diet and other appropriate measures. It lowers plasma cholesterol and lipoprotein levels by acting as a selective, competitive HMG-CoA reductase inhibitor and reduces liver cholesterol synthesis ${ }^{9}$.

Received May 5, 2021

Accepted June 15, 2021

Published June 30, 2021 
The tablets presented as immediate-release tablets with 7 hours of biological half-life ${ }^{10}$. The efficiency of atorvastatin in lowering cholesterol is dose-related. It is available in 10, 20, 40, and $80 \mathrm{mg}$ film-coated tablets. To ensure tablets' quality, safety, and efficacy in formulations, developing a new analytical method for quantitative drug analysis in pharmaceutical dosage forms is crucialThe extensive literature survey was conducted and observed few analytical procedures such as UV-Vis ${ }^{11-15}$, FTIR ${ }^{16}$, X-ray diffraction ${ }^{17}$, FTRaman spectroscopy ${ }^{17}$, capillary electrophoresis ${ }^{18-20}$, Voltammetry ${ }^{21-22}$, TLC ${ }^{23-24}$, HPTLC ${ }^{25-26}$, UPLC ${ }^{27-28}$, LCMS ${ }^{29-30}$ and UPLC-MS ${ }^{27,32-33}$ have been reported for the determination of atorvastatin alone or with combination in pharmaceutical dosage forms and biological fluids. The investigation continued with the HPLC technique due to its simplicity, specificity, high sensitivity, and lots of attention in pharmaceutical analysis in dosage forms and biological fluids ${ }^{34-38}$. Several HPLC methods were studied ${ }^{39-43}$ but required a high flow rate, run time, and internal standard to quantify their biological fluids due to multiple preparation steps and recovery varied in each volumetric process. But the developed method's sample preparation is quite simple, just diluted with mobile phase, injected into the system with high precision autosampler. It preferred external standardization since the chromatogram is simpler, less worry about intervening peaks that might compromise the result was easier to process because of only one peak to measure. In addition, it is more convenient and less expensive. Therefore, the extra step of adding the internal standard during sample preparation was excluded. Developing a straightforward and accurate time-consuming process is necessary and validates the procedure as per guidelines, preferably the International Conference on Harmonization (ICH) ${ }^{44-46}$. The proposed HPLC method was precise and sensitive to determine atorvastatin in pharmaceutical formulations.

\section{Experimental}

\subsection{Materials}

Pharmaceutical formulations of atorvastatin such as Lorvast 10 (Tabuk Pharmaceuticals), Astatin 20 (Jamjoom Pharmaceuticals), Lipomax 10 (Saja Pharmaceuticals), and Lipitor 20 (Pfizer) are bought from local markets. Acetonitrile, dipotassium hydrogen orthophosphate $\left(\mathrm{K}_{2} \mathrm{HPO} 4\right)$, and orthophosphoric acid $\left(\mathrm{H}_{3} \mathrm{PO}_{4}\right)$ are obtained from Sigma Aldrich. All other reagents are of analytical grade and applied without any additional purification. The carbonate buffer ( $\mathrm{pH}-9.4)$ was made by dissolving sodium carbonate $(26.5 \mathrm{~g})$, and sodium bicarbonate $(21 \mathrm{~g})$ in $500 \mathrm{ml}$ distilled water.

\subsection{Instrumentation}

The chromatography was performed on Shimadzu LC-
2010 CHT HPLC system containing autosampler, quaternary pump with the degassing unit, and SPD-20A photodiode array detector. Integration of the chromatograms produced by LC solution software. The column used was the $\mathrm{C}_{18}$ ODS hypersil column (250 $\mathrm{mm} \times 4.6 \mathrm{~mm}, 5 \mu \mathrm{m})$.

\subsection{Chromatographic conditions}

The HPLC separation was performed with the $\mathrm{C}_{18}$ ODS hypersil column $(250 \mathrm{~mm} \times 4.6 \mathrm{~mm}, 5 \mu \mathrm{m})$. The mobile phase comprised acetonitrile and $\mathrm{K}_{2} \mathrm{HPO} 4(0.05 \mathrm{M})$ with a ratio $(1: 10, \mathrm{v} / \mathrm{v})$, maintained the buffer $\mathrm{pH}-7$ with $\mathrm{H}_{3} \mathrm{PO}_{4}$. The required amount of $\mathrm{K}_{2} \mathrm{HPO}_{4}(8.7 \mathrm{~g})$ was transferred and dissolved with 1 litre HPLC water, adjusted $\mathrm{pH}-7$ with $\mathrm{H}_{3} \mathrm{PO}_{4}$. The buffer solution was mixed with acetonitrile with a ratio $(10: 1, \mathrm{v} / \mathrm{v})$. The flow rate was regulated at $0.8 \mathrm{ml} / \mathrm{min}$. All samples analysis was performed at room temperature with detection at $215 \mathrm{~nm}$.

2.4. Extraction of atorvastatin from pharmaceuticals Ten tablets $(20 \mathrm{mg} / \mathrm{tablet})$ were grounded in a powder with mortar and pestle, dissolved in $100 \mathrm{ml}$ distilled water, and passed through a column chromatography with a glass column packed with silica gel. The mobile phase was a combination of solvents (water: methanol: glacial acetic acid=4:6:0.5 v/v/v) having different polarities to elute the compound. When it reached optimum length, the resulting separation of compounds was removed and dried in an oven and collected the pure atorvastatin as solid ${ }^{47}$.

\subsection{Methods}

\subsubsection{Procedure for determination of atorvastatin}

A stock solution $(50 \mu \mathrm{g} / \mathrm{ml})$ was transferred into a $25 \mathrm{ml}$ volumetric flask and completed the mark with the mobile phase to make solutions in the concentration range $0.2-5.5 \mu \mathrm{g} / \mathrm{ml}$. The UV detector detected the eluents with a wavelength of $215 \mathrm{~nm}$ and injected $20 \mu \mathrm{l}$ into the HPLC system with a mobile phase flow rate of $0.8 \mathrm{ml} / \mathrm{min}$. The detector response, as peak area against the atorvastatin concentration, was plotted. Consequently, the regression equation was derived.

\subsubsection{Procedure for pharmaceutical formulations}

Five tablets $(20 \mathrm{mg} / \mathrm{tablet})$ were precisely weighed and finely powdered with mortar and pestle. First, $50 \mathrm{mg}$ atorvastatin powder was extracted with the mobile phase, approximately $25 \mathrm{ml}$, followed by another 2 extractions, each with $25 \mathrm{ml}$ mobile phase. After passing on through a $0.45 \mu \mathrm{m}$ millipore filter, the solution was diluted with the mobile phase to concentrate about $50 \mu \mathrm{g} / \mathrm{ml}$. Then, according to need, dilution continued and analyzed using the suggested procedures. Finally, the calibration graphs or regression equations are used to calculate the nominal content of the tablet. 


\subsubsection{Procedure for the determination of atorvastatin in human urine samples}

The aliquot volumes of human urine samples were transferred into a small separating funnel. The carbonate buffer, $\mathrm{pH}-9.4$, was added approximately $5-10 \mathrm{ml}$, ether extract was collected and evaporated. The residue dissolves with the mobile phase, and then a general procedure was followed to determine the nominal content of atorvastatin using the corresponding regression equation.

\subsection{Validation}

\subsubsection{System Suitability}

The system suitability tests are a fundamental part of the liquid chromatographic method. It showed the separation efficiency of the process by separating two important close components with a specific term resolution. It is also determined with precision by selecting the highest concentration in the linear dynamic range with five independent analyses and calculating the $\%$ relative standard deviation (\%RSD).

\subsubsection{Solution stability}

The standard solution of atorvastatin and its pharmaceutical samples are determined at room temperature. Therefore, the \%RSD of respective solutions was evaluated within a day and continued for another seven days for the same solutions.

\subsubsection{Specificity and selectivity}

The proposed method's specificity and selectivity were assessed by separating the atorvastatin in the presence of common excipients such as starch, glucose, fructose, and lactose. Also, \% RSD was calculated for the retention time and peak area.

\subsubsection{Linearity}

The proposed method's linearity was plotted between atorvastatin concentration and peak area. The linearity estimated with linear regression analysis and calculated using the least square method. The parameters limit of detection (LOD) and limit of quantitation (LOQ) were determined based on the detector response and slope of the regression equation.

\subsubsection{Accuracy and precision}

The accuracy and precision were estimated within the linear dynamic range. Three concentrations were selected (low, medium, and high). The precision results established with \%RSD calculated with five independent analyses executed at each concentration level within one day (intraday precision) and seven consecutive days (interday precision). The accuracy was determined with recovery experiments carried out by the standard addition method. The reference solutions $(50,100,150 \%)$ spiked with pharmaceutical formulations, and the final volume was completed with the mobile phase. Finally, the total amount is established using the calibration curve or linear regression equation.

\section{Results and Discussion}

The chromatographic conditions were optimized and achieved by varying solvent combinations with mobile phase formation and different columns. The best findings were attained with a mobile phase combination of acetonitrile and $\mathrm{K}_{2} \mathrm{HPO}_{4}(0.05 \mathrm{M})$ having a ratio $(1: 10, v / v)$. Thus, the specificity of the chromatographic method was excellent without any interference from the dosage form. The atorvastatin eluted at 3.65 minutes with a total run time of 5 minutes and resolved good shape and baseline (Figure 2).

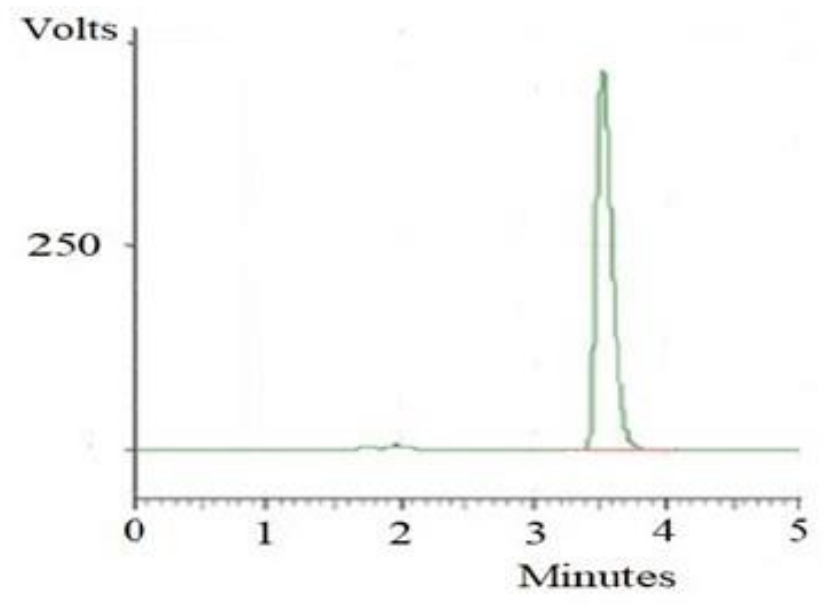

Figure 2. The chromatogram of atorvastatin was attained by the proposed method

\subsection{System suitability}

The system suitability parameter of the suggested method was assessed with five independent analyses of
$5 \mu \mathrm{g} / \mathrm{ml}$ atorvastatin reference solution. The \% RSD was found to be $0.29 \%$ within the range of $\pm 2 \%$, per ICH guidelines. 


\subsection{Specificity}

The atorvastatin was well separated in the presence of common excipients. The chromatographic peak shape was excellent for specificity. The other peaks of excipients were not detected within the run time. Therefore, the proposed method is selective for the determination of atorvastatin in pharmaceutical formulations. The \% RSD of retention time and peak area was $0.32-0.38$ and $0.35-0.44 \%$, respectively.

\subsection{Solution stability}

The solubility of atorvastatin was evaluated with reference and pharmaceutical dosage solutions. The SD and RSD of respective solutions were within the range of $0.28 \pm 0.67$ and $0.35 \pm 0.88 \%$, respectively. All solutions were maintained at $25^{\circ} \mathrm{C}$ for seven days and noticed no significant differences in the peak areas.

\subsection{Linearity}

The proposed method's linearity was determined by selecting the concentration range between $0.2-5.5 \mu \mathrm{g} / \mathrm{ml}$. Then, the linearity range was calculated using the least square method and rectilinear within the range of $0.25-3.8 \mu \mathrm{g} / \mathrm{ml}$ (Figure 3). The calibration data presented the regression equation mentioned in Table 1 with a correlation coefficient close to unity under optimal experimental conditions.

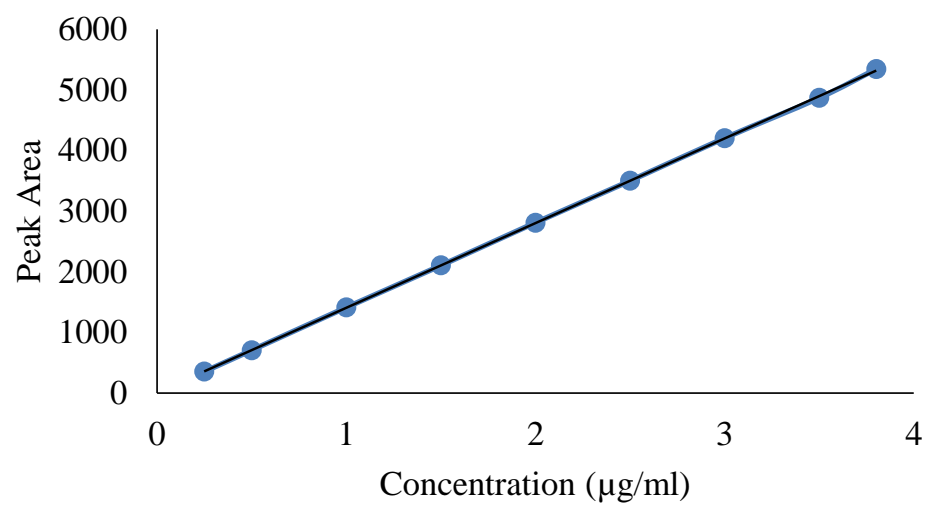

Figure 3. Calibration curve of atorvastatin in pharmaceutical formulation.

Table 1. Summary of optical and regression characteristics of the current method for the determination of atorvastatin.

\begin{tabular}{|c|c|}
\hline Parameters & Atorvastatin \\
\hline Linear dynamic range $(\mu \mathrm{g} / \mathrm{ml})$ & $0.25-3.8$ \\
\hline Regression equation & $\mathrm{y}=1398.3 \mathrm{x}+8.5613$ \\
\hline Correlation coefficient $\left(\mathrm{r}^{2}\right)$ & 0.9999 \\
\hline $\mathrm{LOD}(\mu \mathrm{g} / \mathrm{ml})$ & 0.21 \\
\hline $\mathrm{LOQ}(\mu \mathrm{g} / \mathrm{ml})$ & 0.64 \\
\hline Retention time $\left(\mathrm{t}_{\mathrm{R}}\right)$ minute & 3.65 \\
\hline Number of theoretical plates $(\mathrm{N})$ & 1042.5 \\
\hline
\end{tabular}

\subsection{Accuracy and precision}

The intraday and interday precision analysis was conducted for atorvastatin within the linear dynamic range. Therefore, three concentrations $(1,2$, and $3 \mu \mathrm{g} / \mathrm{ml}$ ) were selected for pure and pharmaceutical formulations. The resulted data tabulated in Table 2 and Table 3. The \%RSD was between $0.37-1.62 \%$ and $0.4-1.41 \%$ for pure and pharmaceutical samples outcomes from intraday and interday analysis. The standard addition method was performed to determine its accuracy due to that computed \% recovery studies. The \% recovery and \% RSD results were satisfactory and were within the range of $98.1-99.8 \%, 0.32-1.56 \%$ (Table 4), and these results were within the range of 98 $102 \%$ and $\pm 2 \%$, respectively, per ICH guidelines. 
Table 2. Determination of atorvastatin in pure form.

\begin{tabular}{|c|c|c|c|c|c|c|}
\hline \multirow{2}{*}{$\begin{array}{c}\text { Proposed } \\
\text { methods }\end{array}$} & \multicolumn{2}{|c|}{ Amount $(\mu \mathrm{g} / \mathrm{ml})$} & \% Recovery & \% RSD & SAE $^{\mathrm{a}}$ & $\mathrm{CL}^{\mathrm{c}}$ \\
\cline { 2 - 7 } & Taken & Found $\pm \mathrm{SD}^{\mathrm{a}}$ & & & & \\
\hline \multirow{3}{*}{ Intraday } & 1 & $0.992 \pm 0.012$ & 99.2 & 1.21 & 0.005 & 0.015 \\
& 2 & $1.972 \pm 0.015$ & 98.6 & 0.76 & 0.007 & 0.019 \\
\hline \multirow{3}{*}{ Interday } & 3 & $2.994 \pm 0.011$ & 99.8 & 0.37 & 0.004 & 0.014 \\
& 1 & $0.987 \pm 0.016$ & 98.7 & 1.62 & 0.007 & 0.019 \\
& 2 & $1.985 \pm 0.019$ & 99.3 & 0.96 & 0.009 & 0.024 \\
\hline & 3 & $2.991 \pm 0.017$ & 99.7 & 0.57 & 0.008 & 0.021 \\
\hline
\end{tabular}

Mean for 5 independent analyses. ${ }^{\text {a }} \mathrm{SD}$, standard deviation, RSD, relative standard deviation; ${ }^{\mathrm{b}} \mathrm{SAE}$, standard analytical error; ${ }^{c}$ C.L., confidence limit at $95 \%$ confidence level and 4 degrees of freedom $(t=2.776)$.

Table 3. Determination of atorvastatin in pharmaceutical formulations.

\begin{tabular}{|c|c|c|c|c|c|c|}
\hline \multirow{2}{*}{$\begin{array}{c}\text { Proposed } \\
\text { methods }\end{array}$} & \multicolumn{2}{|c|}{ Amount $(\mu \mathrm{g} / \mathrm{ml})$} & \% Recovery & \% RSD & SAE $^{\mathrm{b}}$ & $\mathrm{CL}^{\mathrm{c}}$ \\
\hline & Taken & Found $\pm \mathrm{SD}^{\mathrm{a}}$ & & & & \\
\hline & 1 & $0.995 \pm 0.014$ & 99.5 & 1.41 & 0.006 & 0.017 \\
\hline \multirow{3}{*}{ Intraday } & 2 & $1.987 \pm 0.017$ & 99.4 & 0.86 & 0.008 & 0.021 \\
\hline \multirow{3}{*}{ Interday } & 3 & $2.992 \pm 0.012$ & 99.7 & 0.40 & 0.005 & 0.015 \\
\hline & 1 & $0.991 \pm 0.015$ & 99.1 & 1.51 & 0.007 & 0.019 \\
\hline & 2 & $1.978 \pm 0.014$ & 98.9 & 0.71 & 0.006 & 0.017 \\
\hline & 3 & $2.997 \pm 0.013$ & 99.9 & 0.43 & 0.005 & 0.016 \\
\hline
\end{tabular}

Mean for 5 independent analyses. ${ }^{a} \mathrm{SD}$, standard deviation, RSD, relative standard deviation; ${ }^{\mathrm{b}} \mathrm{SAE}$, standard analytical error; ${ }^{c}$ C.L., confidence limit at $95 \%$ confidence level and 4 degrees of freedom $(t=2.776)$.

Table 4. Standard addition method for the determination of atorvastatin in pharmaceutical formulations.

\begin{tabular}{|c|c|c|c|c|c|c|c|}
\hline \multirow{2}{*}{$\begin{array}{l}\text { Proposed } \\
\text { methods }\end{array}$} & \multicolumn{3}{|c|}{ Amount $(\mu \mathrm{g} / \mathrm{ml})$} & \multirow{2}{*}{$\%$ Recovery } & \multirow{2}{*}{$\% \mathrm{RSD}^{\mathrm{a}}$} & \multirow{2}{*}{$\mathrm{SAE}^{\mathrm{b}}$} & \multirow{2}{*}{$\mathrm{CL}^{\mathrm{c}}$} \\
\hline & Taken & Added & Found $\pm \mathrm{SD}^{\mathrm{a}}$ & & & & \\
\hline \multirow{3}{*}{$\begin{array}{l}\text { Intraday } \\
\text { Lorvast } 10\end{array}$} & 1 & 0.5 & $1.488 \pm 0.021$ & 99.2 & 1.41 & 0.009 & 0.026 \\
\hline & 1 & 1 & $1.978 \pm 0.019$ & 98.9 & 0.96 & 0.008 & 0.024 \\
\hline & 1 & 1.5 & $2.489 \pm 0.015$ & 99.6 & 0.60 & 0.007 & 0.019 \\
\hline \multirow{3}{*}{ Astatin 20} & 1 & 0.5 & $1.477 \pm 0.023$ & 98.5 & 1.56 & 0.010 & 0.029 \\
\hline & 1 & 1 & $1.983 \pm 0.025$ & 99.2 & 1.26 & 0.011 & 0.031 \\
\hline & 1 & 1.5 & $2.459 \pm 0.020$ & 98.4 & 0.81 & 0.008 & 0.024 \\
\hline \multirow{3}{*}{ Lipomax 10} & 1 & 0.5 & $1.471 \pm 0.014$ & 98.1 & 0.95 & 0.007 & 0.017 \\
\hline & 1 & 1 & $1.988 \pm 0.021$ & 99.4 & 1.06 & 0.009 & 0.026 \\
\hline & 1 & 1.5 & $2.492 \pm 0.018$ & 99.7 & 0.72 & 0.008 & 0.022 \\
\hline \multirow{3}{*}{$\begin{array}{l}\text { Interday } \\
\text { Lorvast } 10\end{array}$} & 1 & 0.5 & $1.493 \pm 0.019$ & 99.5 & 1.27 & 0.009 & 0.026 \\
\hline & 1 & 1 & $1.968 \pm 0.015$ & 98.4 & 0.76 & 0.007 & 0.019 \\
\hline & 1 & 1.5 & $2.477 \pm 0.022$ & 99.1 & 0.89 & 0.010 & 0.029 \\
\hline \multirow{3}{*}{ Astatin 20} & 1 & 0.5 & $1.491 \pm 0.012$ & 99.4 & 0.81 & 0.005 & 0.014 \\
\hline & 1 & 1 & $1.971 \pm 0.008$ & 98.6 & 0.41 & 0.004 & 0.010 \\
\hline & 1 & 1.5 & $2.494 \pm 0.013$ & 99.8 & 0.52 & 0.006 & 0.016 \\
\hline \multirow{3}{*}{ Lipomax 10} & 1 & 0.5 & $1.495 \pm 0.011$ & 99.7 & 0.74 & 0.005 & 0.014 \\
\hline & 1 & 1 & $1.969 \pm 0.017$ & 98.5 & 0.86 & 0.008 & 0.022 \\
\hline & 1 & 1.5 & $2.486 \pm 0.008$ & 99.4 & 0.32 & 0.004 & 0.009 \\
\hline
\end{tabular}

Mean for 5 independent analyses. ${ }^{\text {a }} \mathrm{SD}$, standard deviation, RSD, relative standard deviation; ${ }^{\mathrm{b}} \mathrm{SAE}$, standard analytical error; ${ }^{\mathrm{c}}$ C.L., confidence limit at $95 \%$ confidence level and 4 degrees of freedom $(\mathrm{t}=2.776)$. 


\subsection{Robustness}

The robustness of the current method relative to each operational parameter was verified and explored. In addition, the minor variations in the mobile phase composition and buffer $\mathrm{pH}$ were studied, affecting the peak area and retention time change. The robustness of the method was reviewed with a $3 \mu \mathrm{g} / \mathrm{ml}$ atorvastatin reference solution. The current process's $\%$ recovery and $\%$ RSD were in the range of 98.35-99.41 and $0.23-0.82 \%$. The results suggested that the recommended procedure is robust and excellent for the quantification of atorvastatin.

\subsection{Ruggedness}

The ruggedness of the method was assessed following the mentioned procedure using a different model of HPLC and column. The \% recovery and \% RSD resultant were in the range of $98.35-99.41$ and $0.23-$ $0.82 \%$.

\subsection{Reference method}

The proposed method was compared with a developed reference method ${ }^{42}$. The analysis was performed with a $\mathrm{C}_{18}$ column $(25 \mathrm{~cm} \times 4.6 \mathrm{~mm})$ containing a mobile phase of methanol:water:acetonitrile: orthophosphoric acid $(85: 10: 4: 1 \mathrm{v} / \mathrm{v} / \mathrm{v} / \mathrm{v})$. The linearity of the reference method was wider, 3.96-1000 $\mu \mathrm{g} / \mathrm{ml}$. Due to that, most likely, it is challenging to apply it for the determination of atorvastatin in biological fluids. The flow rate was maintained at $1.8 \mathrm{ml} / \mathrm{min}$, which required lots of solvents, and also, ruggedness results were not presented. Therefore, developing a method with less flow rate $(1 \mathrm{ml} / \mathrm{min})$ with a linear dynamic range of $0.25-3.8 \mu \mathrm{g} / \mathrm{ml}$ is appropriate for quantifying atorvastatin in bulk and pharmaceuticals and biological fluids. The ruggedness studies were performed to verify $\%$ recovery and \%RSD were within the range of 98102 and $\pm 2 \%$, respectively, as per ICH guidelines.

\subsection{Application of the proposed method with the biological fluid}

The proposed method has been expanded to determine atorvastatin in a spiked human urine sample. A known concentration of atorvastatin was spiked and followed the above-recommended procedure. The $\%$ recovery and \% RSD were in the range of $98.22-98.78 \%$ and $0.635-1.982 \%$, respectively, indicating excellent results for the determination of atorvastatin in the human urine sample.

\section{Conclusion}

The current HPLC method is simple, accurate, and reproducible. It helps to determine atorvastatin in pharmaceutical formulations and biological fluids. Though, currently, numerous HPLC methods are presented for the quantification of atorvastatin. The considerable benefits of the proposed method include short retention time, stability of the solution, no need for prior separation or purification before analysis. As well, the chromatographic method has a more comprehensive linear dynamic range with good accuracy and precision. Furthermore, the technique can estimate the unabsorbed atorvastatin in urine samples. The statistical parameter and recovery data reveal the excellent accuracy and precision of the proposed method. The proposed method could be valuable and suitable for determining atorvastatin in bulk, pharmaceutical formulations and human urine samples.

\section{References}

1- K. J. Udaya, H. M. M. B. Herath, P. V. N. Kaushalya, Method development, validation, and concentration determination of metformin hydrochloride and atorvastatin calcium using UVvisible spectrophotometry, J. Anal. Bioanal. Tech., 2021, 12, 428.

2- S. Sun, R. Wang, J. Fan, G. Q. Zhang, H. Zhang, Effects of danshen tablets on pharmacokinetics of atorvastatin calcium in rats and its potential mechanism, Pharma. Bio., 2018, 56, 104-108.

3- L. Garza, J. Dols, M. Gillespie, An initiative to improve primary prevention of cardiovascular disease in adults with type II diabetes based on the ACC/AHA(2013) and ADA(2016) guidelines, J. American Associa. Nurse Pract., 2017, 29, 606-611.

4- K. Lampropoulos, A. Megalou, G. Bazoukis, G. Tse, A. Manolis, Pre-loading therapy with statins in patients with angina and acute coronary syndromes undergoing PCI, J. Interven. Cardiol., 2017, 30, 507-513.

5- O. F. Cruz-Correa, R. B. Leon-Cachon, H. A. Barrera-Saldana, X. Soberon, Prediction of atorvastatin plasmatic concentrations in healthy volunteers using integrated pharmacogenetics sequencing, Pharmacog., 2017, 18, 121-131.

6- T. J. Dennison, J. C. Smith, R. K. Badhan, A. R. Mohammed, Fixed-dose combination orally disintegrating tablets to treat cardiovascular disease: formulation, in vitro characterization and physiologically based pharmacokinetic modelling to assess bioavailability, Drug Design, Develop. Ther., 2017, 11, 811-826.

7- H. Eng, R. J. Scialis, C. J. Rotter, J. Lin, S. Lazzaro, M. V. Varma, L. Di, B. Feng, M. West M, A. S. Kalgutkar, The antimicrobial agent fusidic acid inhibits organic anion transporting polypeptide-mediated hepatic clearance and may potentiate statin-induced myopathy, Drug Metabol. Dispos., 2016, 44, 692-699.

8- P. Virani, R. Sojitra, H. Raj, V. Jain, A review on irbesartan co-administered with atorvastatin for the treatment of cardiac risk, J. Crit. Rev., 2014, 1, $25-28$. 
9- M. Manikandan, K. Kannan, S. Thirumurugu, R. Manavalanet, Design and evaluation of amlodipine besilate and atorvastatin calcium tablets, Res. J. Pharm. Bio. Chem. Sci., 2012, 3, 425-434.

10-H. Lennernas, Clinical pharmacokinetics of atorvastatin, Clin. Pharma., 2003, 42, 1141-1160.

11-M. M. Salim, M. E. E. Sharkasy, M. Walash, F. Belal, Genetic Algorithm with model-updatingbased PLS regression for the spectrophotometric determination of clopidogrel, atorvastatin, and aspirin in the presence of its degradation product, $\mathbf{J}$. Appl. Spectros., 2020, 87, 568-578.

12-Y. Bilal, K. Selcuk. UV and first derivative spectrophotometric methods for the estimation of atorvastatin in pharmaceutical preparations, J. Adv. Pharm. Res., 2018, 2, 89-94.

13-M. A. A. Sobhy, M. A. A. Lobna, A. M. M. Maha, Spectrophotometric determination of atorvastatin calcium and rosuvastatin calcium in bulk and dosage form using p-dimethylaminobenzaldehyde, J. Appl. Pharm., 2017, 9, 233.

14-A. Alshabrawy, M. Ahmed, A. Nageh, Sensitive spectrophotometric determination of atorvastatin in pharmaceutical formulation by ion pair complexation with pararosaniline hydrochloride, J. Adv. Pharm. Res., 2017, 1, 193-200.

15- A. A. Ramadan, M. Hasna, S. Jenan, Determination of atorvastatin calcium in pure and its pharmaceutical formulations using iodine in acetonitrile by uv-visible spectrophotometric method, Int. J. Pharm. Pharma. Sci., 2015, 7, 427-433.

16-M. Sharma, I. Mehta, Surface stabilized atorvastatin nanocrystals with improved bioavailability, safety and antihyperlipidemic potential, Sci. Rep., 2019, 9, 16105.

17-S. Dimitra, G. Christos, Kontoyannis, Identification and quantitative determination of atorvastatin calcium polymorph in tablets using FT-Raman spectroscopy, Talanta., 2008, 74, 1066-1070.

18-A. Mahesh, Capillary electrophoresis method development for simultaneous determination of atorvastatin and ezetimibe from solid dosage form, J. Young Pharm., 2017, 9, 120-123.

19-S. S. Blanka, H. Gabriel, S. S. Istvan, K. Bela, K. Hajnal, Simultaneous determination of atorvastatin and ezetimibe from combined pharmaceutical products by micellar electrokinetic capillary chromatography, Braz. J. Pharm. Sci., 2017, 53, e16122.

20- A. H. Said, S. E. Eman, Y. S. Maissa, A. E. Z. Badr, Development and validation of HPLC and $\mathrm{CE}$ methods for simultaneous determination of amlodipine and atorvastatin in the presence of their acidic degradation products in tablets, Acta Pharma., 2016, 66, 479-490.
21-W. A. Silva, L. G. de Almeida, F. N. Feiteira, F. S. Semaan, R. Q. Aucelio, R. M. Dornellas, W. F. Pacheco, Novel electrochemical determination of atorvastatin by monitoring the suppression of a lead probe, Anal. Lett., 2021, 54, 541-557.

22-F. A. Ali, High sensitivity determination of atorvastatin calcium in pharmaceuticals and biological fluids using adsorptive anodic stripping voltammetry onto surface of ultra-trace graphite electrode, Curr. Anal. Chem., 2018, 14, 92-100.

23- A. R. Abdul, A. A. Hussen, M. Mohammad, TLC simultaneous determination of amlodipine, atorvastatin, rosuvastatin and valsartan in pure form and in tablets using phenyl-modified aleppo bentonite, Int. J. Pharm. Pharm. Sci., 2014, 6, 180-188.

24-A. G. Nikalje, V. P. Choudhari, Validated TLC method for simultaneous quantitation of atorvastatin, ezetimibe, and fenofibrate in bulk drug and formulations, Acta Chromatogra., 2011, 23, 267-280.

25-R. M. Shroff, P. A. Bachhav, S. B. Ganorkar, A. A. Shirkhedkar, S. S. Chalikwar, Analytical and bioanalytical profile for atorvastatin: an exploratory review, Europ. J. Pharma. Med. Res., 2020, 7 , 271-282.

26-T. B. Deshmukh, S. S. Deo, Development and validation of novel HPTLC method for the simultaneous estimation of atorvastatin calcium and telmisartan in tablet dosage form, Int. J. Pharm. Chem. Bio. Sci., 2018, 8, 82-90.

27-K. Wadhwa, A. C. Rana, A review on liquid chromatographic methods for the bioanalysis of atorvastatin, Future J. Pharm. Sci., 2021, 7, 1-19.

28-A. N. Waghmare, B. S. Muddukrishna, S. G. Vasantharaju, Analytical method development and validation of simultaneous estimation of amlodipine and atorvastatin by RP-UPLC, Mintage J. Pharm. Med. Sci., 2014, 3, 22-25.

29-E. Z. Asma, K. C. Lily, W. Yang, S. Vadim, S. L. C. Diana, Simultaneous LC-MS/MS analysis of simvastatin, atorvastatin, rosuvastatin and their active metabolites for plasma samples of obese patients underwent gastric bypass surgery, $\mathrm{J}$. Pharm. Biomed. Anal., 2019, 164, 258-267.

30-D. Hossein, H. Mehrdad, Method validation of amlodipine and atorvastatin by liquid chromatography-mass spectrometry (LC-MS) method in human plasma, Cogent Med., 2016, 3, 1129790.

31-M. C. Sakac, Z. Vujic, Z. Vujcic, B. Markovic, D. Vasiljevic, LC-MS/MS method for quantification of atorvastatin, o-hydroxy atorvastatin, p-hydroxy atorvastatin, and atorvastatin lactone in rat plasma, Acta Chromatog., 2016, 28, 281-298.

32-B. Xia, Y. Li, Y. Zhang, M. Xue, X. Li, P. Xu, 
T. Xia, S. Chen, UHPLC-MS/MS method for determination of atorvastatin calcium in human plasma: application to a pharmacokinetic study based on healthy volunteers with specific genotype, J. Pharm. Biomed. Anal., 2018, 160, 428-435.

33-C. Liyun, Z. Zhijie, W. Xipei, T. Lan, M. Liping, H. Guodong, L. Heping, Z. Shilong, Simultaneous determination of atorvastatin and its metabolites in human plasma by UPLC-MS/MS, Anal. Met., 2017, 9, 1038-1045.

34-A. Zahoor, H. Munir, R. Junaid, S. Hussain, S. Naveed, M. O. Alam, K. Khanum, F. Qamar, S. Khan, A RP-HPLC Method for Simultaneous estimation of Chlorpheniramine Maleate, Paracetamol and Phenylephrine Hydrochloride in Bulk, RADS J. Pharm. Pharm. Sci., 2018, 6, 53-58.

35-S. Asif, S. Naveed, K. Usmanghani, M. T. Alam, G. Sarwer, Method development and validation of RP-HPLC method for estimation of Eplerenone in bulk and pharmaceutical formulations, RADS J. Pharm. Pharm. Sci., 2017, 5, 20-26.

36-A. Zahoor, H. Munir, S. Hussain, K. Khanum, S. Naveed, K. Usmanghani, Development and Validation of RP-HPLC Method for Quantitative Estimation of Vinpocetine in Intellan Capsule. RADS J. Pharm. Pharm. Sci., 2016, 4, 28-33.

37-F. Khalid, S. Gul, M. N. Khan, M. T. Alam, UV spectrophotometric method for estimation of moxifloxacin $\mathrm{HCl}$ in tablet dosage form and comparative study of its different brands, RADS J. Pharm. Pharm. Sci., 2015, 3, 41-49.

38-S. Shakeel, S. Naveed, K. Usmanghani, G. Sarwar, M. T. Alam. RP-HPLC Simultaneous Analysis of Glimepiride and NSAIDs in Active Pharmaceutical Ingredient, Formulations, and Human Serum, RADS J. Pharm. Pharm. Sci., 2015, 3, 58-64.

39-W. Alshitari, F. Al-Shehri, D. A. El-Hady, H. M. Albishri, A simple HPLC method containing greener modifier and slighter temperature elevated for simultaneous determination of three statin drugs in tablets, Acta Chromatogr., 2021, doi:10.1556/1326.2021.00896.

40-M. M. Zareh, M. Z. Saad, W. S. Hassan, M. E. Elhennawy, M. K. Soltan, M. M. Sebaiy, Gradient HPLC method for simultaneous determination of eight sartan and statin drugs in their pure and dosage forms, Pharm., 2020, 13, 32.

41-K. Wadhwa, A. C. Rana, Development and validation of HPLC-UV based bioanalytical method for the quantification of atorvastatin in rat plasma, World J. Adv. Res. Rev., 2020, 7, 121-132.

42-S. Alam, S. Saleem, S. Naveed, H. Dilshad, F. Qamar, T. Alam, H. Sadia, M. Karim, A. Khan, HPLC Method Development and Validation of Atorvastatin Calcium in Bulk and Tablet Dosage Form, RADS J. Pharm. Pharm. Sci., 2018, 6, 83-87.

43-F. Hamid, F. Qamar, S. Naveed, S. Saleem, S. Basheer, S. Khan, H. Sadia, K. Usmanghani, A Novel RP-HPLC Method for Simultaneous Determination of Moxifloxacin and Atorvastatin, RADS J. Pharm. Pharm. Sci., 2017, 5, 50-56.

44-United States Food and Drug Administration. Guidance for industry: Validation of analytical procedures: methodology Q2B, 1996.

45-United States Food and Drug Administration. Guideline for industry: text on validation of analytical procedures: ICH Q2A, 1995.

46-International conference on the harmonization of the technical requirements for registration of pharmaceuticals for human use. Validation of analytical procedures: text and methodology $\mathrm{ICH}$ Q2(R1), 1996.

47-A. A. Judeh, A. Sarief, Y. Umar, O. Ashwaq, S. M. Haque, Development, computational studies and validation of spectrophotometric method of metformin hydrochloride in pharmaceutical formulations, J. Chil. Chem. Soc., 2020, 65, 4895-4899. 